\title{
Development of a multiplex PCR to identify Salmonella, Leptospira and Brucella species in tissue samples
}

\author{
Truong Quang Lam, Byung-il Yoon, Tae-Wook Hahn* \\ College of Veterinary Medicine and Institute of Veterinary Science, Kangwon National University, \\ Chuncheon 200-701, Korea
}

(Received: August 4, 2011; Revised: January 3, 2012; Accepted: January 5, 2012)

\begin{abstract}
We have developed and optimized a multiplex polymerase chain reaction (mPCR) for simultaneous detection of Brucella, Salmonella and Leptospira with high sensitivity and specificity. Three pairs of oligonucleotide primers were designed to specifically amplify the targeted genes of Salmonella, Leptospira and Brucella species with sizes of 521, 408 and $223 \mathrm{bp}$, respectively. The mPCR did not produce any nonspecific amplification products when tested against 15 related species of bacteria. The sensitivity of the mPCR was $100 \mathrm{fg}$ for Brucella and $1 \mathrm{pg}$ for both Salmonella and Leptospira species. In the field application, kidney, liver and spleen were collected from wild rats and stray cats and examined by mPCR. The high specificity and sensitivity of this mPCR assay provide a valuable tool for diagnosis and for the simultaneous and rapid detection of three zoonotic bacteria that cause disease in both humans and animals. Therefore, this assay could be a useful alternative to the conventional method of culture and single PCR for the detection of each pathogen.
\end{abstract}

Keywords : Brucella, Leptospira, Salmonella species, multiplex PCR, tissue samples

\section{Introduction}

Brucellosis, Salmonellosis and Leptospirosis are serious diseases that occur worldwide and affect wild and domestic animals as well as humans [5, 9, 11]. Although these diseases were once largely eradicated, they are now a continuing and apparently increasing global problem. Epidemiological studies have shown that rodents and other wild animals often act as reservoirs and vectors for a number of infectious agents that cause disease in farm livestock and domestic pets [12]. Recent evidence indicates that Brucella, Salmonella and Leptospira infections have also been reported in wildlife, rodents and cats [3, 10, 19, 25, 28]. Brucella, Salmonella and Leptospira species are intracellular, slow growing and facultatively fastidious. Bacteriological isolation is usually employed for diagnosis. However, the isolation of these pathogens, with the exception for Salmonella, is usually difficult, time-consuming and laborious. These diseases can be diagnosed by serology, but many factors may cause false positive and negative results $[1,2,5,15]$.

To overcome these diagnostic problems, molecular techniques such as polymerase chain reaction (PCR) have been used for increased sensitivity and specificity. Numerous PCRs have been developed for the detection of Brucella [1, 13, 15, 16, 21, 28], Salmonella and Leptospira [2, 5, 6, 14, 26, 29] have been applied to DNA extracted from bacterial cells, blood and tissue samples. In diagnostic laboratories, the use of PCR is limited by cost, time and sometimes the availability of an adequate test sample volume. mPCR diagnostics could help to overcome these difficulties and increase the diagnostic capacity of PCR. mPCR is cost effective and has the potential to save considerable amounts of time. Several mPCRs for the detection of Brucella, Salmonella and Leptospira have been described and successfully applied; examples include mPCRs for the simultaneous detection of Brucella spp. and Salmonella abortus ovis [23], the detection of both Brucella spp. and Leptospira spp. from aborted bovine fetuses [20], and the detection of both Brucella canis and Leptospira

\footnotetext{
*Corresponding author

Tel: +82-33-250-8671, Fax: +82-33-244-2367

E-mail: twhahn@kangwon.ac.kr
} 
interrogans in canine semen [11].

We have attempted to detect these three pathogens in various tissues of rodents and cats. Because single-PCR detection of each pathogen is too laborious, time consuming and wasteful of reagents, we attempted to develop mPCR for this purpose. The aim of this investigation was to develop an MPCR assay that could be used for the simultaneous detection of Salmonella, Leptospira and Brucella in a single reaction with highly sensitivity and specificity, using as template either DNA extracted directly from tissue samples or bacterial culture. The availability of such a rapid test should simplify and streamline diagnostic testing for these three important pathogens of humans and animals.

We report the development of the first MPCR assay for the sensitive and reliable detection of Salmonella, Leptospira and Brucella based on the combination and optimization of published primer sets. The specificity and sensitivity of the mPCR were tested, and the results were compared with those of single-PCR detection. We also report the application of $\mathrm{mPCR}$ for the direct detection of these pathogens in tissue samples of stray cats and rodents.

\section{Materials and Methods}

\section{Bacterial strains}

All reference strains of Salmonella ( $S$. Enteritidis and Typhimurium), Leptospira (L. interrogans serovar Pomona, $L$. interrogans serovar Icterohemorrhagiae, and $L$. interrogans serovar Bratislava), Brucella species ( $B$. abortus, B. abortus vaccine strain RB51, B. ovis and B. canis) and another 15 bacterial strains were used in this study (Table 1).

\section{Genomic DNA extraction}

Total DNA was extracted from bacterial cells and tissue specimens using the Genomic DNA extraction kit (YGT100 and YGB100; RBC, Taiwan) according to the manufacturer's protocol. Briefly, for tissue samples, 3 types of organ tissues (kidney, liver and spleen) were taken out and homogenized by Tissue Lyzer (QIAGEN, Germany). Cultured bacterial cells were transferred to microcentrifuge tubes and centrifuged for $1 \mathrm{~min}$ at $14,000 \mathrm{rpm}$. The supernatant was then discarded. DNA concentration and purity were determined by a spectrophotometer at the wavelengths of $260 \mathrm{~nm}$ (GENESYS 10S UV; Thermo Scientific, USA) Extracted DNA was
Table 1. Bacterial strains used in this study and the results of $\mathrm{mPCR}$

\begin{tabular}{llc}
\hline \hline \multicolumn{1}{c}{ Genera/species } & \multicolumn{1}{c}{ Strain } & mPCR \\
\hline Brucella abortus & ATCC 17385 & + \\
Brucella abortus RB51 & RB51 & + \\
Brucella ovis & ATCC 25840 & + \\
Brucella canis & ATCC 23365 & + \\
Leptospira i. Pomona & ATCC 23478 & + \\
Leptospira i. Icterohemorrhagiae & ATCC 43642 & + \\
Leptospira i. Bratislava & ATCC 23578 & + \\
Salmonella Enteritidis & ATCC 13076 & + \\
Salmonella Typhimurium & ATCC 14028 & + \\
Salmonella Gallinarum & ATCC 9184 & + \\
Salmonella Choleraesuis & ATCC 13312 & + \\
Streptococcus suis & ATCC 43765 & - \\
Bacillus subtilis & ATCC 6633 & - \\
Bordetella bronchiseptica & ATCC 10580 & - \\
Clostridium tetani & ATCC 19406 & - \\
Escherichia coli & ATCC 10536 & - \\
Enterobacter & ATCC 35028 & - \\
Shigella flexineri & ATCC 12023 & - \\
Haemophilus parasuis & ATCC 19417 & - \\
Achloplasma laidawi & ATCC 23206 & - \\
Listeria monocytogenes & ATCC 19117 & - \\
Mycoplasma pneumoniae & ATCC 15492 & - \\
Mycoplasma hyopneumoniae & ATCC 25934 & - \\
Mycoplasma gallisepticum & ATCC 1961 & - \\
Pasteurella multocida & ATCC 43137 & - \\
Staphylococus aureus & ATCC 29213 & - \\
\hline
\end{tabular}

stored at $-20^{\circ} \mathrm{C}$ for further use.

\section{Primer selection and optimization of $\mathrm{MPCR}$}

The target genes, oligonucleotide primers and expected product sizes for each pathogen are shown in Table 2 . Based on size differences of approximately 100 between amplicons, we selected each primer as follows: the $B C S P 31$ primers amplified a $223 \mathrm{bp}$ fragment of a gene encoding a cell surface protein (BCSP31) of Brucella spp. [1]; the LipL41 primers amplified a 408 bp fragment from the gene encoding LipL41 of Leptospira spp. [27]; and the invA primers amplified a $521 \mathrm{bp}$ fragment of the invA gene encoding a 54-kDa protein of Salmonella spp. [26]. Selected oligonucleotide primers were synthesized by Bioneer (Korea).

For optimization of the mPCR, the amplification was carried out in a $50 \mu \mathrm{L}$ reaction mixture containing 10 $\mu \mathrm{L}$ of $5 \times$ PCR buffer $(50 \mathrm{mM} \mathrm{NaCl}, 50 \mathrm{mM}$ Tris- $\mathrm{HCl}$, $\mathrm{pH} 9.0) ; 250 \mu \mathrm{M}$ each deoxynucleotide triphosphate; 2 
Table 2. List of oligonucleotide primers used in this study

\begin{tabular}{|c|c|c|c|c|}
\hline Genus/species & Target gene & Primer set $\left(5^{\prime} \rightarrow 3^{\prime}\right)$ & Length of PCR product (bp) & References \\
\hline Leptospira spp. & LipL41 & $\begin{array}{l}\text { GGCTATCTCCGTTGCACTCTTTG } \\
\text { ATCGCCGACATTCTTTCTACACG }\end{array}$ & 408 & [27] \\
\hline Brucella spp. & BCSP 31 & $\begin{array}{l}\text { TGGCTCGGTTGCCAATATCAA } \\
\text { CGCGCTTGCCTTTCAAGGTCTG }\end{array}$ & 223 & {$[1]$} \\
\hline Salmonella spp. & $\operatorname{Inv} A$ & $\begin{array}{l}\text { TTGTTACGGCTATTTTGACC } \\
\text { CTGACTGCTACCTTGCTGAT }\end{array}$ & 521 & {$[26]$} \\
\hline
\end{tabular}

$\mathrm{mM} \mathrm{MgCl}_{2}$; and $1 \mathrm{U}$ of GoTaq Flexi DNA polymerase (Promega, USA). Each primer (Table 2) was added at the following final concentrations: 15 pmol for BCSP31 and 20 pmol for $i n v A$ and LipL41. One microliter of diluted template DNA from reference strains or $5 \mu \mathrm{L}$ of template DNA from a tissue sample was added to each reaction mixture. The final volume of the reaction mixture was adjusted to $50 \mu \mathrm{L}$ with sterile deionized distilled water. The magnesium chloride concentration $\left(\mathrm{Mg}^{2+} 1,1.5,2,2.5\right.$ and $\left.3 \mathrm{mM}\right)$, primer concentration and template DNA volume were tested as variables for optimal $\mathrm{mPCR}$ results. All $\mathrm{mPCR}$ reactions were performed in a thermocycler (PC100; MJ Research, USA) with the following temperature cycling parameters: initial denaturation at $95^{\circ} \mathrm{C}$ for $5 \mathrm{~min}$ followed by 40 cycles of denaturation at $95^{\circ} \mathrm{C}$ for $30 \mathrm{sec}$, primer annealing at various temperatures from 54 to $60^{\circ} \mathrm{C}$ for $30,40,50$ or $60 \mathrm{sec}$ for optimization, primer extension at $72^{\circ} \mathrm{C}$ for 30 or $60 \mathrm{sec}$, and a final extension at $72^{\circ} \mathrm{C}$ for $15 \mathrm{~min}$.

Ten microliters of the amplified product was evaluated for expected size by electrophoresis on a $1 \%$ agarose gel in 1X Tris-boric acid-EDTA buffer [TBE: $0.089 \mathrm{M}$ Trisbase, $0.089 \mathrm{M}$ boric acid, and 0.002 M EDTA (pH 8.0)] at 100 volts. After electrophoresis, amplification products were detected by visualization of the bands under UV light after staining with Gel Red (Komabiotech, Korea). A 100-DNA ladder (Bioneer, Korea) was used as molecular marker to indicate the size of the amplicons.

\section{Specificity and sensitivity of optimized mPCR}

To determine the specificities of the optimized mPCRs, genomic DNA prepared from Salmonella, Leptospira, Brucella spp. and 15 reference strains (Table 1) was used in mPCR. To study the influence of DNA template from tissue samples on mPCR amplification of Salmonella, Leptospira, and Brucella spp., extracted DNA from kidney, liver and spleen tissues of rodents and stray cats was used for testing the mPCR. The sequences of the amplicons were conrmed by sequence analysis and a
BLAST search of the GenBank database. The DNA used as sequencing templates consisted of PCR products purified with the HiYield Gel/PCR DNA mini kit (YDF100; RBC, Taiwan).

The detection limit of the $\mathrm{mPCR}$ assay was determined using limiting dilutions of DNA. DNA from B. abortus, $S$. Enteritidis and $L$. Pomona was quantified spectrophotometrically and diluted to $100 \mathrm{ng} / \mu \mathrm{L}$ with sterile deionized distilled water. Serial dilutions from 100 ng to $10 \mathrm{fg}$ were made, and $1 \mu \mathrm{L}$ of each dilution was analyzed in a $50 \mu \mathrm{L}$ PCR and mPCR. The lowest concentration visible on an agarose gel was set as the detection limit.

\section{Results}

\section{Optimal condition of mPCR}

Three pairs of oligonucleotide primers were designed to amplify specific regions of BCSP31, LipL41 and invA from the Brucella, Leptospira and Salmonella genomes, respectively. Primer BCSP31 was designed to amplify an approximately $223 \mathrm{bp}$ fragment from Brucella. Primer LipL41 was designed to amplify an approximately $408 \mathrm{bp}$ fragment from Leptospira. The invA primer pair amplifies approximately $521 \mathrm{bp}$ of the invA gene encoding a 54-kDa protein in Salmonella spp. (Fig. 1).

To optimize the mPCR, we tested all of the primers with several combinations of annealing temperature, extension time, number of cycles and primer concentration. The concentration of magnesium chloride was varied from 1 to $3 \mathrm{mM}$. At low magnesium concentrations, some of the expected PCR fragments were faint or nondetectable, while nonspecific PCR products of various sizes were amplified at high magnesium concentrations. From these results, the optimum magnesium concentration for the assay was determined to be $2 \mathrm{mM}$. The concentrations of all primers were adjusted to $20 \mathrm{pmol}$, which resulted in differences in the intensities of the 
A

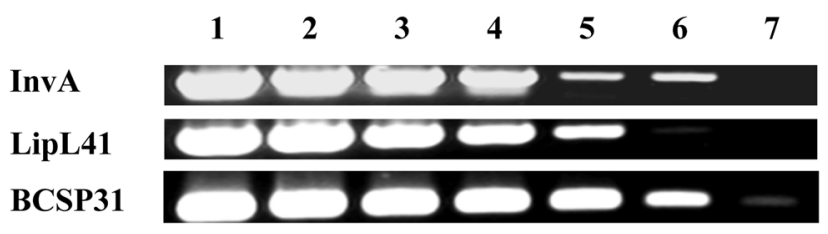

B

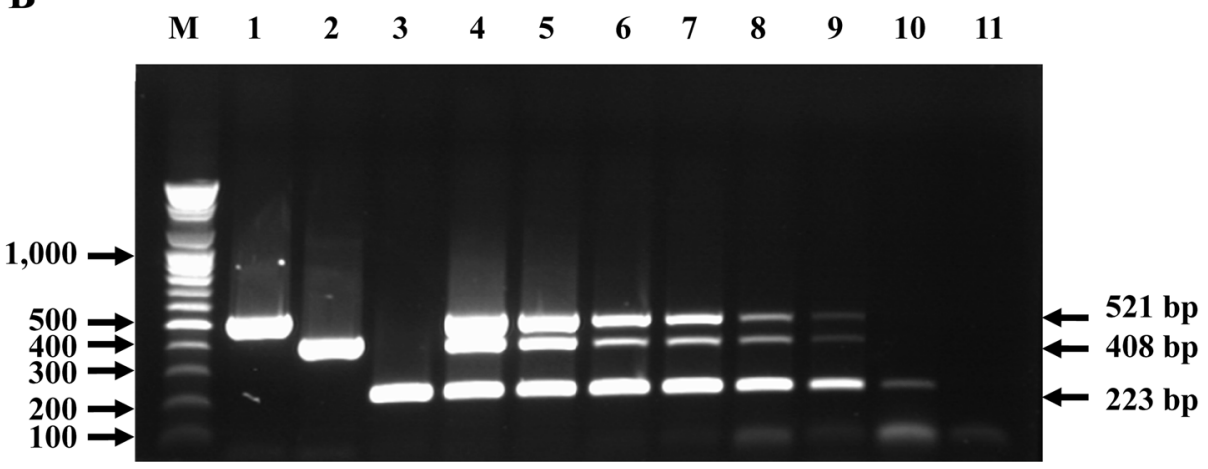

Fig. 1. Sensitivity of single PCR for Salmonella, Leptospira and Brucella target genes (A) and the multiplex PCR for simultaneous amplification of all bacterial target DNA (B). Multiplex PCR products were separated in a $1 \%$ agarose gel and stained with Gel Red. Each target DNA fragment was extracted, and 10-fold serial dilutions were prepared at concentrations of $100 \mathrm{ng}$ to $100 \mathrm{fg}$. One microliter of each concentration of each target DNA was subjected to single PCR for Salmonella, Leptospira and Brucella using specific primer pairs (A, lanes 1 7), and mixed DNA was subjected to mPCR. (B) Lanes 1 3: single PCR for each pathogen, S. Enteritidis (521 bp), L. Pomona (408 bp) and B. abortus (223 bp), respectively; Lanes 4 10: mPCR with mixed DNAs at each concentration; Lane 11: negative control; Lane M: 100 bp DNA ladder.

amplified DNA fragments. Initially, the intensity of the BCSP31-specific amplicon was higher than other PCR products; however, the intensities of all the amplicons became almost identical after the concentration of the BCSP31 primers was decreased to $15 \mathrm{pmol}$. The amplification condition showing the best resolution of all amplicons included an annealing step at $57^{\circ} \mathrm{C}$ for 40 sec, an extension step at $72^{\circ} \mathrm{C}$ for $30 \mathrm{sec}$ and 40 cycles of amplification (Fig. 1B).

\section{Specificity of mPCR}

The specificity of primer pair for each pathogen was analyzed by single PCR. As shown in Fig. 1A, each primer pair amplifies the corresponding target gene, clearly yielding the amplicon sizes of $521 \mathrm{bp}$ for Salmonella, $408 \mathrm{bp}$ for Leptospira and $223 \mathrm{bp}$ for Brucella. Three amplification products were observed simultaneously in an mPCR in which a mixture of chromosomal DNA of Brucella, Leptospira and Salmonella was used as a template (Fig. 1B). To determine the specificity of the primers selected, genomic DNA from
15 different strains of 13 bacterial species were assayed. None of the amplification products were generated from any of the other bacterial strains (Table 1). This result indicates that the mPCR assays are highly specific for the simultaneous detection of these three pathogens. No PCR product was obtained from a negative control with no template.

\section{Sensitivity of mPCR}

Comparisons of the sensitivity of single PCR and mPCR detection using BCSP31, invA and LipL41 primers for detecting purified Brucella, Salmonella and Leptospira DNA are shown in Fig. 1. The threshold sensitivity of the PCR assay was determined by testing serial dilutions of Brucella, Salmonella and Leptospira DNA from $100 \mathrm{ng}$ to $100 \mathrm{fg}$. The detection limits of single PCRs and mPCR were found to be the same; as little as $100 \mathrm{fg}$ of Brucella DNA was detected after 40 cycles of amplification, in comparison with $1 \mathrm{pg}$ of Salmonella and Leptospira DNA. 


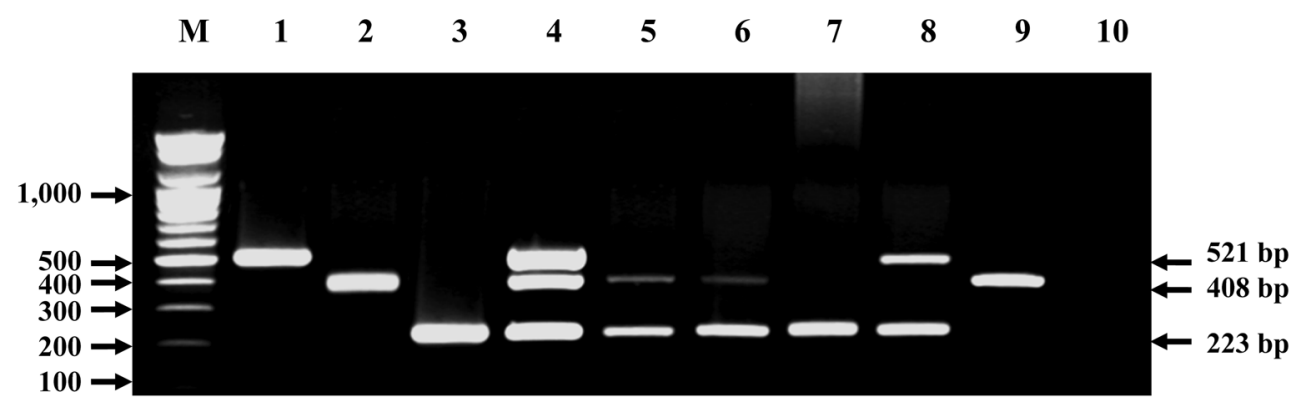

Fig. 2. Agarose gel electrophoresis of DNA fragments generated by multiplex PCR directly from tissue samples. Lanes 1 3: S. Enteritidis, L. Pomona and B. abortus, respectively; Lane 4: combination of Salmonella, Leptospira and Brucella; Lanes 5, 6 and 9: DNA template isolated from kidney of rodent and stray cat; Lane 7: spleen of a stray cat; Lane 8: liver of a rodent; Lane 10: negative control; M: $100 \mathrm{bp}$ DNA ladder.

\section{Application of mPCR for tissue samples from rodents and cats}

This mPCR was developed for detection of Salmonella, Leptospira and Brucella in tissue samples of rodents and stray cats. The DNA templates were extracted directly from spleen, kidney and liver using a commercial kit and subjected to the mPCR using three specific primer sets (Table 2). As shown in Fig. 2, a clear amplification product was obtained for all tested tissue samples; these results also reveal that our mPCR was able to simultaneously detect all three pathogens. The PCR amplicons produced by mPCR were confirmed as regions of the Brucella and Leptospira genome by automated sequencing and subsequent entry of the sequence into the BLAST search engine (data not shown).

\section{Discussion}

The diagnosis of Brucella, Leptospira and Salmonella is typically based on isolation from clinical specimens or serologic evidence of antibodies. Culturing takes days to weeks but has the advantage of detecting the organism directly. For rapid testing of clinical samples or for field surveys, immunologic methods are used. However, antigen-antibody interactions can be complicated by nonspecific interactions, and false positives from vaccinated animals with high levels of circulating antibodies can be misdiagnosed as active infections.

PCR is a promising option for the diagnosis of various pathogens, and it is a potentially useful method for the detection of Brucella, Leptospira and Salmonella species from isolated bacteria, blood, semen or highly contaminated tissues [1, 2, 5, 11, 13, 14, 16, 17, 20]. Previous studies have also demonstrated the successful application of single PCR using specific primer pairs for the detection of Brucella species in bacterial cultures or blood samples $[1,16]$, for the detection of Leptospira species in clinical samples [14, 27] and for the detection of Salmonella species [26]. However, single PCR only allows the detection of nucleic acid from one specific pathogen at a time. Our recent attempts to use individual PCR for the detection of those three pathogens in various tissues of wild rodents and cats demonstrated that this technique is relatively costly and time-consuming. Therefore, in this study, we improved the diagnostic value of these PCR methods by taking a multiplex approach. The mPCR has the advantage of simultaneous detection of multiple pathogens and has been proven to be sensitive, specific and cost-effective. It can be useful in diagnosis, screening and surveillance of flocks [9].

The sensitivity comparison of this developed mPCR with single PCRs for individual bacteria (data not shown) revealed that the sensitivity of the MPCR was comparable to that of a single PCR with the same limit of detection: Brucella, $100 \mathrm{fg}$; Leptospira, $1 \mathrm{pg}$; and Salmonella species, $1 \mathrm{pg}$. The detection limits of both single PCRs and mPCR for Leptospira and Salmonella species, but not Brucella, are similar to those previously reported in the literature $[16,24,26]$. The excellent sensitivity of PCR reported by Navarro et al. [16] using the primers $\mathrm{B} 4 / \mathrm{B} 5(\mathrm{BCSP} 31)$ in the diagnosis of Brucella species in bacterial culture and blood samples showed that the primers B4/B5 amplified $5 \mathrm{pg}$ of purified genomic DNA [16], compared with $100 \mathrm{fg}$ in this study. The concentrations of primers, dNTPs, $\mathrm{MgCl}_{2}$ 
and Taq polymerase in this PCR assay were different from those in the report of Navarro et al. [16], which may account for the difference in sensitivity.

According to previous publications $[1,7,13,16,26$, 27], the primers used in mPCR were specific for Brucella, Leptospira and Salmonella and were applicable to all species and biovars among those 3 bacterial genera. Previous publications on single PCR showed that each primer pair was highly specific for each pathogen. In examining the specificity of primers for Brucella genus, Da Costa et al. [7] also surveyed 98 non-Brucella bacteria and found that all organisms were negative for amplification of the BCSP31 gene. For the genus Leptospira, successful amplification of the predicted 408 bp amplicon from all Leptospira interrogans was described; an assessment of specificity showed that the gene could not be amplified in a panel of 15 nonLeptospira species [27]. For the genus Salmonella, the invA primer pair is specific [26], but no studies have evaluated the specificity of these primers for all species in the genus. In this study, to further examine the specificity of each primer pair used in $\mathrm{MPCR}$, all 4 strains of Brucella, 3 strains of Leptospira and 4 strains of Salmonella were tested and gave specific amplification of the correct predicted product size. In addition, the specificity of the primers used for mPCR has also been tested against 15 closely related bacterial species and a variety of other common pathogens, and the absence of amplification of the DNA from these bacterial species indicates that this assay is highly specific for Brucella, Leptospira and Salmonella.

Several studies have indicated that the inhibition of PCR can be a confounding factor because unknown inhibitors may be released from tissues in DNA extraction. The presence of inhibitors could affect the sensitivity of PCR, especially for various tissue samples such as milk, blood, semen and urine $[2,4,5,8,14$, $16,18,22]$. The sensitivity of $\mathrm{mPCR}$ could also be affected by modification of the original PCR protocol $[13,21]$. Interestingly, the mPCR described in this paper is the first successful application of mPCR using the B4/ B5 (BCSP31) primer pair. These primers were used to amplify a 223 bp region encoding a $31-\mathrm{kDa}$ immunogenic BCSP31 of Brucella spp. from kidney, liver and spleen samples of rodents and cats. The use of tissue samples did not reduce the ability of the PCR or MPCR to detect specific target genes or different combinations of the three infectious pathogens. This result suggests that other primer pairs might also be used for the direct detection of Brucella species in tissue samples. The positive PCR results for Salmonella were confirmed by isolation of the pathogen from the tissue (data not show), but no further sequencing was performed on those samples. As the isolation of Leptospira and Brucella are normally difficult, time-consuming and laborious, the positive PCR products for Leptospira and Brucella were confirmed by sequencing. To confirm the identity of the PCR product, the nucleotide sequence was determined and compared with the Brucella and Leptospira sequences published on NCBI-BLAST. We conducted a sequence analysis of 18 fragments (10 samples of Brucella and 8 samples of Leptospira) amplified with BCSP31 and LipL41 primers. Sequence analysis of the $233 \mathrm{bp}$ fragment using BCSP31 and the $408 \mathrm{bp}$ fragment using LipL41 yielded perfect matches in the BLAST search.

In summary, the mPCR described in this study provides an improved capacity to detect Salmonella, Leptospira and Brucella simultaneously in a single reaction. The assay appears to be very specific and highly sensitive, with a limit of $100 \mathrm{fg}$ for Brucella and 1 pg for both Salmonella and Leptospira strains. mPCR can be used to test clinical samples such as blood and tissue samples as well as bacterial culture. This method is not a substitute for single PCR, but it can be used to reduce the number of required tests and deliver results more rapidly and cheaply.

\section{Acknowledgments}

This study was supported funding from the Veterinary Science Technical Development projects in Animal, Plant and Fisheries Quarantine and Inspection Agency, and technically supported by Institute of Veterinary Science, Kangwon National University, Korea.

\section{References}

1. Baily GG, Krahn JB, Drasar BS, Stoker NG. Detection of Brucella melitensis and Brucella abortus by DNA amplification. J Trop Med Hyg 1992, 95, 271275.

2. Bal AE, Gravekamp C, Hartskeerl RA, De MezaBrewster J, Korver H, Terpstra WJ. Detection of leptospires in urine by PCR for early diagnosis of leptospirosis. J Clin Microbiol 1994, 32, 1894-1898.

3. Cho MK, Kee SH, Song HJ, Kim KH, Song KJ, 
Baek LJ, Kim HH, Oh HB, Kim YW, Chang WH. Infection rate of Leptospira interrogans in the field rodent, Apodemus agrarius, in Korea. Epidemiol Infect 1998, 121, 685-690.

4. Cocolin L, Manzano M, Astori G, Botta GA, Cantoni C, Comi G. A highly sensitive and fast nonradioactive method for the detection of polymerase chain reaction products from Salmonella serovars, such as Salmonella Typhi, in blood specimens. FEMS Immunol Med Microbiol 1998, 22, 233-239.

5. Cohen ND, Martin LJ, Simpson RB, Wallis DE, Neibergs HL. Comparison of polymerase chain reaction and microbiological culture for detection of salmonellae in equine feces and environmental samples. Am J Vet Res 1996, 57, 780-786.

6. Cohen ND, Neibergs HL, McGruder ED, Whitford HW, Behle RW, Ray PM, Hargis BM. Genus-specific detection of salmonellae using the polymerase chain reaction (PCR). J Vet Diagn Invest 1993, 5, 368-371.

7. Da Costa M, Guillou JP, Garin-Bastuji B, Thiebaud M, Dubray G. Specificity of six gene sequences for the detection of the genus Brucella by DNA amplification. J Appl Bacteriol 1996, 81, 267-275.

8. Fekete A, Bantle JA, Halling SM. Detection of Brucella by polymerase chain reaction in bovine fetal and maternal tissues. J Vet Diagn Invest 1992, 4, 79-83.

9. Henegariu O, Heerema NA, Dlouhy SR, Vance GH, Vogt PH. Multiplex PCR: critical parameters and stepby-step protocol. Biotechniques 1997, 23, 504-511.

10. Jones PW, Twigg GI. Salmonellosis in wild mammals. J Hyg (Lond) 1976, 77, 51-54.

11. Kim S, Lee DS, Suzuki H, Watarai M. Detection of Brucella canis and Leptospira interrogans in canine semen by multiplex nested PCR. J Vet Med Sci 2006, 68, 615-618.

12. Le Moine V, Vannier P, Jestin A. Microbiological studies of wild rodents in farms as carriers of pig infectious agents. Prev Vet Med 1987, 4, 399-408.

13. Leal-Klevezas DS, Martinez-Vazquez IO, LopezMerino A, Martinez-Soriano JP. Single-step PCR for detection of Brucella spp. from blood and milk of infected animals. J Clin Microbiol 1995, 33, 30873090.

14. Merien F, Amouriaux P, Perolat P, Baranton G, Saint Girons I. Polymerase chain reaction for detection of Leptospira spp. in clinical samples. J Clin Microbiol 1992, 30, 2219-2224.
15. Morata P, Queipo-Ortuno MI, Reguera JM, Miralles F, Lopez-Gonzalez JJ, Colmenero JD. Diagnostic yield of a PCR assay in focal complications of brucellosis. J Clin Microbiol 2001, 39, 3743-3746.

16. Navarro E, Escribano J, Fernandez J, Solera J. Comparison of three different PCR methods for detection of Brucella spp in human blood samples. FEMS Immunol Med Microbiol 2002, 34, 147-151.

17. O'Leary S, Sheahan M, Sweeney T. Brucella abortus detection by PCR assay in blood, milk and lymph tissue of serologically positive cows. Res Vet Sci 2006, 81, 170-176.

18. Pathmanathan SG, Cardona-Castro N, SanchezJimenez MM, Correa-Ochoa MM, Puthucheary SD, Thong KL. Simple and rapid detection of Salmonella strains by direct PCR amplification of the hilA gene. J Med Microbiol 2003, 52, 773-776.

19. Repina LP, Nikulina AI, Kosilov IA. A case of human infection with brucellosis from a cat. Zh Mikrobiol Epidemiol Immunobiol 1993, 66-68.

20. Richtzenhain LJ, Cortez A, Heinemann MB, Soares RM, Sakamoto SM, Vasconcellos SA, Higa ZM, Scarcelli E, Genovez ME. A multiplex PCR for the detection of Brucella spp. and Leptospira spp. DNA from aborted bovine fetuses. Vet Microbiol 2002, 87, 139-147.

21. Romero C, Gamazo C, Pardo M, Lopez-Goni I. Specific detection of Brucella DNA by PCR. J Clin Microbiol 1995, 33, 615-617.

22. Savio ML, Rossi C, Fusi P, Tagliabue S, Pacciarini ML. Detection and identification of Leptospira interrogans serovars by PCR coupled with restriction endonuclease analysis of amplified DNA. J Clin Microbiol 1994, 32, 935-941.

23. Sharifzadeh A, Doosti A, Khaksar K. Simultaneous detection of Brucella spp. and Salmonella abortus ovis by multiplex PCR. Res J Bio Sci 2008, 3, 109-111.

24. Soumet C, Ermel G, Fach P, Colin P. Evaluation of different DNA extraction procedures for the detection of Salmonella from chicken products by polymerase chain reaction. Lett Appl Microbiol 1994, 19, 294-298.

25. Srivastava L, Sehgal S, Thukral SS, Kumari S, Rajagopal R. Prevalence of various Salmonella serotypes in the wild rodents of South India. J Commun Dis 1984, 16, 219-222.

26. Swamy SC, Barnhart HM, Lee MD, Dreesen DW. Virulence determinants invA and spvC in salmonellae 
isolated from poultry products, wastewater, and human sources. Appl Environ Microbiol 1996, 62, 3768-3771.

27. Theodoridis D, Bohmer J, Homuth M, StrutzbergMinder K. Development of a novel ELISA for serodiagnosis of leptospirosis and additional detection of pathogenic Leptospira by polymerase chain reaction for veterinary routine diagnostics. Rev Cubana Med Trop 2005, 57, 49-50.

28. Tiller RV, Gee JE, Frace MA, Taylor TK, Setubal
JC, Hoffmaster AR, De BK. Characterization of novel Brucella strains originating from wild native rodent species in North Queensland, Australia. Appl Environ Microbiol 2010, 76, 5837-5845.

29. Vinodh R, Raj GD, Govindarajan R, Thiagarajan V. Detection of Leptospira and Brucella genomes in bovine semen using polymerase chain reaction. Trop Anim Health Prod 2008, 40, 323-329. 